\title{
Impacto del COVID-19 en el periodismo latinoamericano: entre la precariedad laboral y las secuelas psicológicas
}

\author{
COVID-19 Impact on Latin American Journalism: Between job \\ insecurity and psychological consequences
}

Impacto do Covid-19 no jornalismo latino-americano: entre insegurança no trabalho e consequências psicológicas

Ruth de Frutos, Universidad de Málaga, Málaga, España (ruth.defrutos@uma.es)

Sebastián Sanjurjo, Federación Internacional de Periodistas, Buenos Aires, Argentina (sebastian.sanjurjo@ifj-la.org)

RESUMEN | La COVID-19 ha generado un nuevo desafío global en términos de la seguridad delos periodistas. El epicentro de la pandemia se trasladó en junio de 2020 a América Latina, donde el desconocimiento sobre el coronavirus, unido a la pluralidad de respuestas políticas y la diversidad de mecanismos puestos en funcionamiento por los medios y las empresas de comunicación han afectado directamente al ejercicio profesional. Este artículo busca analizar las principales consecuencias laborales y emocionales para los profesionales de la información desde México hasta Argentina durante los primeros 100 días de la COVID-19 en la región, por medio de un cuestionario distribuido entre las 18 organizaciones afiliadas de la Federación Internacional de Periodistas en América Latina, pertenecientes a 16 países $(\mathrm{N}=95)$. El agravamiento de las debilidades estructurales del periodismo latinoamericano, unido a la precarización y a los efectos del teletrabajo han sido algunos de los principales resultados del estudio, que será discutido con otros similares realizados a escala nacional en Argentina y Brasil en futuras investigaciones. Las conclusiones de este trabajo, que representa a un grupo determinado de estudio, ofrecerán futuras líneas de investigación para un proceso y universo más amplio, que deberán ser tenidas en cuenta para mejorar los protocolos de protección de los periodistas freelance y dependientes de medios públicos, privados y comunitarios en América Latina.

PALABRAS CLAVE: COVID-19; pandemia; periodistas; América Latina; Federación Internacional de Periodistas. 
ABSTRACT /COVID-19 has created a new global challenge in terms ofjournalist safety. The focus of the pandemic shifted to Latin America in June 2020, where ignorance about the coronavirus, along with the plurality of political responses and the diversity of mechanisms put in place by the media and communication companies have directly affected professional practice. This article aims to analyze the main labor and emotional consequences for information professionals from Mexico to Argentina during the 100 days of the virus in the region, through a questionnaire distributed among the 18 affiliated organizations of the International Federation ofJournalists in Latin America, belonging to 16 countries ( $N=95)$. The aggravation of the structural weaknesses of Latin American journalism, together with precariousness and self-care, have been some of the main results of the study, which will be discussed with other similar ones conducted nationally in Argentina and Brazil. The conclusions of this research will offer future lines of research that should be considered to improve the protection protocols for freelance journalists and those dependent on public, private and community media in Latin America.

KEYWORDS: COVID-19; pandemic; journalists; Latin America; International Federation of Journalists.

RESUMO | A Covid-19 criou um novo desafio global em termos de segurança para jornalistas. O foco da pandemia mudou-se para a América Latina em junho de 2020, onde o desconhecimento sobre o coronavírus, juntamente com a pluralidade de respostas políticas e a diversidade de mecanismos implementados pela mídia e as empresas de comunicação, afetaram diretamente a prática profissional. Este artigo tem como objetivo analisar as principais consequências trabalhistas e emocionais dos profissionais da informação desde o México até a Argentina durante os 100 dias da Covid-19 na região, utilizando um questionário distribuído entre as 18 organizações afiliadas da Federação Internacional de Jornalistas da América Latina, pertencente a 16 países $(\mathrm{N}=95)$. $\mathrm{O}$ agravamento das fragilidades estruturais do jornalismo latino-americano, juntamente com a precariedade e os efeitos do teletrabalho, foram alguns dos principais resultados do estudo, que será discutido com outros semelhantes realizados nacionalmente na Argentina e no Brasil em futuras pesquisas. As conclusões desta pesquisa, que representa um grupo determinado de estudo, oferecerão futuras linhas de investigação para um processo e universo mais amplo, que deverão ser levadas em consideração para a melhoria dos protocolos de proteção para jornalistas freelancers e dependentes de mídia pública, privada e comunitária na América Latina.

PALABRA CHAVE: COVID-19; pandemia; jornalistas; América Latina; Federação Internacional de Jornalistas. 


\section{INTRODUCCIÓN}

El periodismo es un pilar básico para la democracia, en tanto contribuye a generar una opinión pública y a mantener a la ciudadanía informada sobre asuntos de interés general, lo cual es aún más importante en el contexto de la emergencia sanitaria mundial inédita causada por el COVID-19, con graves repercusiones de salud, económicas y sociales. En dicho contexto, "el periodismo es clave para proporcionar información fidedigna en medio de esta amplia "infodemia", para combatir los mitos y rumores. Sin la acción del periodismo, el contenido falso puede expandirse de manera desenfrenada" (Unesco, 2020, p. 2)

Este rol protagónico se observó desde el siglo XIX, pero la globalización, la masificación de las comunicaciones y el desarrollo de las tecnologías en el siglo XX y XXI han promovido una democratización, contribuyendo a fortalecer la libertad de expresión en el mundo (Soengas-Pérez, 2018; Díaz Nosty, 2018; Castells, 2009). Dicha esencialidad del periodismo es también relevante en la percepción del riesgo por parte de la ciudadanía, ya que es la percepción -y no el riesgo en sí mismo- la que determina la respuesta frente a la crisis (Glik, 2007)

Si bien aún no se han realizado estudios pormenorizados sobre el papel de los medios en la pandemia de COVID-19, es llamativo ver cómo los encuestados del único país de la región analizado por el Reuters Institute for the Study of Journalism (2020) en una encuesta entre usuarios de Internet en seis Estados -Alemania, Argentina, Corea del Sur, España, Estados Unidos y Reino Unido (N=8502)-, son los más escépticos sobre la función de los medios no solo para entender la crisis, sino para reaccionar frente a ella (Retegui \& Becerra, 2020).

El derecho a la información y la libertad de expresión son dos de los pilares del ejercicio profesional del periodismo. Están recogidos en el artículo 19 de la Declaración Universal de los Derechos Humanos (La Declaración Universal..., 1948), el artículo 19 del Pacto Internacional de los Derechos Civiles y Políticos (Pacto Internacional de Derechos..., 1966), así como en sus posteriores desarrollos normativos regionales, como el artículo 13 del Pacto de San José (Convención Americana Sobre Derechos Humanos..., 1969) y nacionales. También son reconocidos en la meta 16.10 de los Objetivos de Desarrollo Sostenible promulgados por las Naciones Unidas. Sin embargo, los profesionales de la información se encuentran con dificultades durante su ejercicio profesional ligadas a la pluralidad, la independencia, la concentración de medios y la propia seguridad de los periodistas (Unesco, 2019).

Dichos cuatro aspectos, que articulan la conceptualización de desarrollo mediático y libertad de expresión para la Unesco (2018), tienen un amplio desarrollo en la literatura académica (de Frutos \& Giannone, 2018; de Frutos, 2014). La propagación del coronavirus ha promovido un desafío sin precedentes en estas 
variables, que aún no ha sido abordado científicamente. Desde que el 11 de marzo de 2020 la Organización Mundial de la Salud (OMS) definiese a la COVID-19 como una pandemia, las respuestas políticas latinoamericanas han sido diversas ${ }^{1}$, lo que ha afectado directamente a las coberturas periodísticas de cada país.

Históricamente, los estudios de comunicación tendieron a focalizarse sobre el análisis de los mensajes y los productos culturales, también en tiempos de pandemia (Casero-Ripollés, 2020; Costa-Sánchez \& López-García, 2020; La et al., 2020; Li et al., 2020). Este artículo tiene como objetivo suplir esa falta de estudios académicos sobre las consecuencias del coronavirus en el ejercicio profesional latinoamericano, examinando el impacto económico y laboral en la profesión, así como los efectos psicológicos y físicos de los profesionales que han cubierto la COVID-19. La pertinencia, el interés y la innovación de esta investigación son de particular relevancia al examinar la situación del periodismo latinoamericano durante la pandemia.

\section{MARCO TEÓRICO}

Desde enero de 2020, los medios de comunicación en todo el mundo incrementaron su cobertura sobre el coronavirus, focalizando la atención en la comunidad médicocientífica (Papapicco, 2020). Los primeros contagios a finales de 2019 en la localidad china de Wuhan se trasladaron rápidamente por vía aérea a Europa y, posteriormente, a América. Esta expansión del virus "ha generado una complicada situación a nivel sanitario, económico y social, que requiere de una labor de comunicación fundamental para que la sociedad comprenda y colabore con las medidas adoptadas" (Costa Sánchez \& López García, 2020, p. 1), primando aún más la labor periodística.

En un contexto de fuerte incertidumbre, la emergencia de las noticias falsas y los bulos evidenció la necesidad de un periodismo "más local y con la exigencia de formar una ciudadanía que requiere conocer la verdad especialmente en tiempos de emergencia sanitaria" (Rodrigo Cano \& Ruiz-Alba, 2021, p. 27).

La llegada del primer caso de coronavirus a la región latinoamericana el 26 de febrero de 2020 vía Brasil (BBC News Mundo, 2020) generó una modificación no solo en las prácticas profesionales, sino también en las políticas empresariales de los medios de comunicación y en las políticas públicas en materia de

1. Solo por citar algunos ejemplos, el presidente mexicano, Andrés Manuel López Obrador, contradijo directamente las recomendaciones de las autoridades sanitarias invitando a los mexicanos a salir a la calle (Humans Rights Watch, 2020a.) Por su parte, el presidente de Brasil, Jair Bolsonaro, minimizó en todo momento los efectos de la crisis sanitaria de COVID-19, considerando al virus una pequeña gripe o un resfriado, posicionamientos que han provocado la destitución de varios ministros de salud(Humans Rights Watch, 2020b.). Por último, el presidente nicaragüense, Daniel Ortega, no declaró ningún tipo de emergencia en respuesta a la pandemia (Delgado, 2020). 
comunicación; algunos países consideraron al periodismo como trabajo esencial y, por ello, lo dotaron de ciertos privilegios, como los permisos de circulación durante el confinamiento de la población. Cabe destacar que la realidad mediática latinoamericana es sumamente compleja, dada la gran diversidad cultural y los diferentes mercados nacionales de medios y sistemas políticos que se desarrollan en la región, unidos con las particularidades de los ecosistemas mediáticos nacionales y los factores que los afectan en cada país (Unesco, 2019).

Las diferentes políticas públicas en la región para la mitigación del virus o la ausencia de ellas han marcado no solo el discurso y la práctica periodística, sino también las agendas de los medios de comunicación y las condiciones laborales de los profesionales de la información ${ }^{2}$, llegando incluso al fallecimiento durante el ejercicio profesional ${ }^{3}$. La Corte Interamericana de Derechos Humanos (2020; Pandemia y Derechos Humanos..., 2020) solicitó que los Estados respetasen el derecho internacional en tiempos de pandemia, protegiendo aquellos esenciales, entre los que están la libertad de expresión y el derecho a la información. Esta esencialidad de la actividad periodística ha sido respetada en los marcos normativos derivados de la emergencia sociosanitaria de la pandemia en algunos países ${ }^{4}$ de la región, mientras que otros han vulnerado este principio ${ }^{5}$.

2. La plataforma de Resiliencia de la Red Global (\#REG4COVID) es un espacio diseñado por la Unión Internacional de Telecomunicaciones (2020) para que reguladores y otros actores puedan compartir información sobre las diferentes medidas.

3. La investigación de Punín y sus colegas (2021) alude a las causas de la muerte de 38 periodistas ecuatorianos entre marzo y diciembre de 2020, que evidencian, según las autoras, la precariedad laboral, el intrusismo profesional y la desatención a las mínimas normas de seguridad para la cobertura, que ha provocado una reacción de la sociedad civil y de los gremios profesionales. 4. En Argentina, el Decreto de Necesidad y Urgencia 297/2020, que establecía el aislamiento social, preventivo y obligatorio desde el 20 de marzo y se prorrogó hasta el 28 de junio de 2020, aludía a distintas actividades esenciales exceptuadas, entre las que se encontraban los trabajadores de medios de comunicación.

5. El 10 de febrero, el Gobierno hondureño decretó el Estado de Emergencia Sanitaria (Decreto PCM-005-2020) y el 16 de marzo, en virtud del PCM 021-2020, un decreto de suspensión de garantías constitucionales durante siete días restringía el derecho a la libertad de expresión, prevista en el artículo 72 de la Constitución, medida que fue revocada por el Decreto Ejecutivo PCM-022-2020. Diversas organizaciones de derechos humanos, como el Comité por la Libre Expresión (2020) denunciaron las limitaciones a la libertad de tránsito de los periodistas, así como su dificultad para conseguir salvoconductos para circular, e incluso una mayor agresividad de las fuerzas de seguridad del Estado hacia la prensa. Por último, se generaron 30 protocolos para distintos sectores profesionales para la reapertura en el país y ninguno se refería al trabajo periodístico. 
La Comisión Económica para América Latina y el Caribe (CEPAL) y el Banco de Desarrollo de América Latina (CAF) explicaban en su informe Las oportunidades de la digitalización en América Latina frente al COVID-19 que "es raro encontrar casos de países donde el éxito relativo en el control y la mitigación de COVID-19 no esté explicado en buena medida por el uso de aplicaciones móviles y sistemas de información soportados en tecnologías digitales" (CEPAL \& CAF, 2020, p. 18). No obstante, diversas organizaciones de la sociedad civil (VV. AA., 2020) alertaban de la peligrosidad de este tipo de controles ligados a la privacidad y a la protección de datos de la ciudadanía en general, y de personas defensoras y periodistas en particular.

Tal y como exponían Estrada-Villaseñor y Moreno-Marquez (2021, p. 111), "el impacto de la COVID-19 ha sido muy alto en el quehacer diario de estos periodistas y pueden identificarse algunas tendencias que venían detectándose antes de la pandemia, tales como el uso de recursos telemáticos, la precarización laboral que se ha intensificado en este periodo, así como las fuentes alternativas a las oficiales". De acuerdo con esta idea y refiriéndose al caso latinoamericano, Navarro Zamora planteaba en su en estudio descriptivo emergente que "el perfil de las y los periodistas y sus condiciones de trabajo inciden en el desarrollo de la actividad y por consecuencia en el cumplimiento al derecho a la información de los ciudadanos, expresado por ellas y ellos" (2021, p. 237), especialmente durante la pandemia. Según la autora, entre las dos situaciones que más afectaron a la profesión periodística destacan la baja seguridad laboral en la contratación -que otros estudios relacionaban directamente con la desregulación de los mercados laborales y el aumento de la flexibilidad, incluso antes de la pandemia, promoviendo dinámicas de pluriempleo, bajos salarios y condiciones de precarización y flexibilización en la profesión periodística (Caminos, 2020) - y los escasos insumos de protección hacia los profesionales que se encargaban de las coberturas en terreno, a lo que habría que añadir el desafío del teletrabajo y el desarrollo digital de la profesión.

Considerando este tercer aspecto, en la región objeto de estudio se observaba una tendencia dominante en los últimos años relacionada con el crecimiento del acceso a contenidos digitales (mayor acceso a Internet ${ }^{6}$, mayor penetración de redes sociales y persistencia del proceso de digitalización, si bien con impacto heterogéneo por zonas), lo que había generado consecuencias en los medios tradicionales derivadas de la migración de contenidos de la televisión, la prensa y la radiodifusión hacia plataformas digitales, además de procesos de concentración infocomunicacional (Becerra \& Mastrini, 2009, 2017; Mastrini \& Becerra, 2006). El temor al contagio

6. "El acceso a Internet constituye una condición sine qua non para el ejercicio efectivo de los derechos humanos hoy en día, incluyendo especialmente los derechos a la libertad de expresión y opinión, asociación y reunión, educación, salud y cultura” (Lanza, 2017). 
por coronavirus y la aplicación de las primeras medidas sanitarias en América Latina desde marzo de 2020 evidenciaron la importancia del trabajo periodístico y de las tecnologías digitales para contrarrestar el aislamiento, difundir medidas profilácticas y facilitar el funcionamiento de los sistemas económicos. Según el Banco de Desarrollo de América Latina (2020), los indicadores más claros de su relevancia fueron precisamente el incremento exponencial del tráfico de Internet, la importancia del teletrabajo y la necesidad de mantener activas las cadenas de aprovisionamiento y de distribución de bienes. Estos tres índices incidieron en todas las actividades profesionales, también en la de los periodistas.

En este contexto, los objetivos de la investigación son analizar las principales consecuencias laborales y emocionales para los profesionales de la información desde México hasta Argentina durante los primeros 100 días de la COVID-19 en América Latina, contribuyendo a describir el perfil del periodismo al inicio de la pandemia, específicamente en torno a sus condiciones laborales y psicológicas.

Esta investigación es pertinente, ya que muestra una valoración regional de los profesionales afiliados a la Federación Internacional de Periodistas (FIP), y oportuna, pues se ha generado un diálogo con estudios similares a nivel global (Federación Internacional de Periodistas, 2020) y también nacional, como las investigaciones realizadas por el Sindicato de Periodistas de Andalucía (2020) o la Federação Nacional dos Jornalistas (2020), pero existía una carencia en el análisis a escala regional.

\section{METOdOLOGÍA}

América Latina ha sido elegida como marco geográfico para desarrollar este estudio por tres razones. En primer lugar, la región ya era una de las más peligrosas para ejercer el periodismo (Unesco, 2019) antes de la pandemia. En segundo lugar, desde junio de 2020 el foco del impacto de la COVID-19 a nivel internacional se concentró en la región: "Cuatro de los 10 países con mayor número de infecciones diarias son latinoamericanos: Brasil, Perú, Chile y México", aseguró el 1 de junio el director de emergencias de la Organización Mundial de la Salud (OMS, 2019)7, Michael Ryan. A diferencia de otras zonas del mundo, las características socioeconómicas latinoamericanas poseen una particularidad que acentúa la propagación del virus: la concentración habitacional en barrios especialmente empobrecidos. En tercery últimolugar, la colaboración de la Federación Internacional de Periodistas a escala latinoamericana en esta investigación transversaliza sus resultados, los que serán utilizados no solo con fines académicos, sino también profesionales, para generar recomendaciones frente a futuras evoluciones del virus.

7. https://www.who.int/es/emergencies/diseases/novel-coronavirus-2019 
Este artículo intenta subsanar la ausencia de investigaciones científicas sobre los efectos en las condiciones de trabajo y en los aspectos psicológicos de los periodistas latinoamericanos durante los 100 primeros días de pandemia en la región (26 de febrero - 5 de junio de 2020), cruzando esta información con la revisión bibliográfica de las políticas públicas para la mitigación del virus en cada uno de los estados de la región y con dos encuestas nacionales realizadas con el mismo objetivo, en Brasil y en Argentina.

El propósito del estudio es el de evaluar el impacto de la COVID-19 para los profesionales de la información, considerando sus condiciones laborales y el ámbito psicoemocional. En este sentido, el diseño de la investigación intenta responder a las siguientes hipótesis:

H1. La pandemia y el aislamiento social han agravado los problemas estructurales del periodismo latinoamericano, profundizando la precarización laboral ya existente.

De esta hipótesis se derivan dos secundarias:

H2. El teletrabajo ha aumentado la precarización laboral de los periodistas en la región, suponiendo mayor carga laboral y mayores responsabilidades.

H3. Las medidas de aislamiento han incidido en las prácticas periodísticas latinoamericanas, afectando no solo la labor profesional, sino también la integridad psicofísica mediante afecciones como el estrés, la ansiedad o las dificultades para descansar.

El diseño metodológico de esta investigación incluyó las siguientes fases: una revisión bibliográfica en materia de precarización laboral; la falta de protección y el desarrollo digital del periodismo durante la pandemia, y la aplicación del cuestionario facilitado a las 18 organizaciones afiliadas de la Federación Internacional de Periodistas (FIP) en América Latina, ubicadas en 16 países de la región. También una discusión posterior de los resultados con otros dos estudios nacionales contemporáneamente en Brasil por la Federação Nacional dos Jornalistas (2020) y en Argentina por el Sindicato de Prensa de Buenos Aires (SiPreBa, 2020).

El cuestionario $(\mathrm{N}=95)$ se realizó de manera electrónica ${ }^{8}$ en tres idiomas español, portugués y francés- considerando los antecedentes de los llevados a cabo por la FIP (2020) y una afiliada (Sindicato de Periodistas de Andalucía, 2020),

8. El cuestionario está disponible en el siguiente enlace: https://docs.google.com/forms/d/ 15st3Th66Mx0PJdlPjRdE0EOgmchJRa9VwmMrCZCIZlw/viewform?edit_requested=true. Consultado el 11 de junio de 2020. 
y se contó con el consentimiento informado y con un enlace de acceso al cuestionario en línea. Las respuestas fueron recibidas entre el 15 de mayo de 2020 y el 5 de junio de 2020, conformándose una muestra no probabilística, dado que el universo objeto de estudio de periodistas latinoamericanos era demasiado vasto $\mathrm{y}$, por ende, indagarlos en su totalidad implicaría una suerte de censo regional que no se relaciona ni con los alcances ni con los objetivos que persigue esta investigación. Se acordó con FIP que el piso mínimo de la investigación sería, al menos, de 50 respuestas, número casi duplicado en la investigación. Dada la accesibilidad de los datos, la proximidad de los investigadores y la ausencia de un censo nacional y regional de los profesionales de la información (Garcés-Prettel et al., 2020), se decidió usar este tipo de muestra y descartar el método probabilístico, que necesitaría de otro tipo de requerimientos en términos de costos y estructura.

Conviene señalar que Brasil fue excluido de la investigación porque la organización afiliada a la FIP, la Federação Nacional dos Jornalistas (Fenaj), elaboró una encuesta similar de ámbito nacional, por lo que se decidió comparar los datos macro regionales con los micro de este país en el epígrafe destinado a la discusión de los resultados. Asimismo, se entabla un diálogo entre los resultados propios con la encuesta elaborada en Argentina por el Sindicato de Prensa de Buenos Aires (SiPreBa) en aquellas categorías comparables relacionadas con precarización laboral y protección y desarrollo digital, principalmente orientado a teletrabajo.

Para conocer si se habían producido cambios en la percepción de los periodistas latinoamericanos sobre su situación laboral y ejercicio profesional y, de ser así, cuáles, durante los 100 primeros días de coronavirus en la región, se elaboró un bloque de tres preguntas. En un primer momento, se preguntó por las condiciones de trabajo previas al primer caso de coronavirus y a la puesta en funcionamiento de medidas de prevención social, obteniendo diez posibilidades (tabla 1).

Posteriormente, se evaluó la situación durante la pandemia, dando siete opciones relacionadas con un posible cambio en la situación laboral de los informantes y, en el caso de responder afirmativamente, pidiendo que detallasen su situación (tabla 2).

En sintonía con estas consideraciones, se preguntó si la empresa había informado al trabajador o la trabajadora sobre las medidas de protección concernientes al COVID-19, dando la posibilidad de cinco respuestas (tabla 3).

Dada la importancia de la conciliación laboral y el teletrabajo evidenciada por diversas organizaciones internacionales durante la pandemia (OMS 2019; Organización Internacional del Trabajo, 2020), se preguntó específicamente por esta modalidad, mediante seis opciones diferentes (tabla 4). 


\section{Situación laboral}

\begin{tabular}{cc}
\hline $\begin{array}{c}\text { Contratado/a en relación de dependencia } \\
\text { jornada completa. }\end{array}$ & $\begin{array}{c}\text { Contratado/a en relación de dependencia } \\
\text { jornada parcial. }\end{array}$ \\
\hline Contratación temporal en jornada completa. & Contratación temporal en jornada parcial. \\
\hline Autónomo/a o freelance para un medio. & Autónomo/a o freelance para varios medios. \\
\hline $\begin{array}{c}\text { Trabajo en un medio (público, privado o } \\
\text { comunitario). Especificar. }\end{array}$ & $\begin{array}{c}\text { Trabajo en varios medios (públicos, privados o } \\
\text { comunitarios). Especificar. }\end{array}$ \\
\hline Jubilado del periodismo o comunicación. & Otras. \\
\hline
\end{tabular}

Tabla 1. Situación laboral de la muestra

Fuente: Elaboración propia.

\section{Posible cambio en la situación laboral derivada de la pandemia}

\begin{tabular}{|c|c|}
\hline Suspensión. & Despido. \\
\hline Obligación de tomar vacaciones. & Reducción de la jornada laboral. \\
\hline $\begin{array}{c}\text { Comunicación de la no renovación del contrato } \\
\text { laboral. }\end{array}$ & Disminución de la demanda de trabajo. \\
\hline \multicolumn{2}{|l|}{ Eliminación de la colaboración u otros. } \\
\hline \multicolumn{2}{|c|}{ Tabla 2. Modificación en la situación laboral de la muestra derivada de la pandemia } \\
\hline \multicolumn{2}{|c|}{ Fuente: Elaboración propia. } \\
\hline \multicolumn{2}{|c|}{ Información sobre medidas de protección del COVID-19 } \\
\hline \multicolumn{2}{|c|}{ Sí, de manera adecuada. } \\
\hline \multicolumn{2}{|c|}{ Sí, tardíamente. } \\
\hline \multicolumn{2}{|c|}{ Sí, aunque de modo insuficiente. } \\
\hline \multicolumn{2}{|c|}{ No. } \\
\hline \multicolumn{2}{|c|}{ Otras. } \\
\hline
\end{tabular}

Tabla 3. Información facilitada por el medio de comunicación o la empresa de comunicación al periodista durante la pandemia

Fuente: Elaboración propia.

Flexibilización del horario laboral.

Reducción del horario laboral debido al cuidado de menores o personas mayores.

Posibilidad de teletrabajar.

Provisión de equipamiento suficiente para la realización del trabajo en casa.

Ninguna medida.

Otras.

Tabla 4. Medidas relacionadas con la conciliación laboral y el teletrabajo

Fuente: Elaboración propia con base en las categorías de la Organización Internacional del Trabajo (2020). 
Jornada laboral

Trabajo más tiempo que antes.

Trabajo menos tiempo que antes.

Trabajo la misma cantidad de horas, pero distribuyo mejor los tiempos y lo hago más tranquilamente.

Trabajo la misma cantidad de horas, pero la organización del trabajo se dificulta.

Percepción sobre esta modalidad de trabajo en remoto

Creo que es una modalidad efectiva.

Creo que es una modalidad que incide peyorativamente en los resultados del trabajo.

Otras.

Tabla 5. Percepción del teletrabajo durante la pandemia

Fuente: Elaboración propia.

Dificultades de movilidad.

Dificultades para el acceso a fuentes institucionales.

Dificultades en el acceso de otro tipo de fuentes.

Falta de equipamiento para el desarrollo profesional.

Falta de capacitación para el teletrabajo.

Otras.

Tabla 6. Dificultades durante el desempeño profesional

Fuente: Elaboración propia.

Para ahondar en la percepción sobre el teletrabajo, se observó si esta modalidad había ampliado o disminuido la carga laboral de los informantes, que podían elegir entre seis respuestas (tabla 5).

Dada esta descripción del periodismo durante la pandemia, tanto a escala internacional (Unesco, 2020) como en las legislaciones derivadas de la prevención del coronavirus en diversos países de la región, se estudiaron las dificultades encontradas en el desempeño profesional, con seis posibilidades multirrespuesta (tabla 6).

Asimismo, era fundamental interesarse por la percepción de los periodistas sobre si el aislamiento social y las medidas adoptadas habían repercutido en la calidad de su trabajo. Para ello, se diseñó una pregunta dicotómica que, en caso afirmativo, debería ser explicada en una respuesta abierta. Con respecto a las medidas de seguridad puestas a disposición por los medios y empresas de comunicación, se preguntó qué suministros y disposiciones habían facilitado las empresas, con opción multirrespuesta (tabla 7). 
Alcohol en gel.

Guantes, gafas, EPI.

Barbijos o mascarillas.

Medidas de distanciamiento social.

Ropa distintiva luminosa para trabajar en las calles.

Acreditaciones o certificados para circular legalmente por la vía pública.

Otras.

Tabla 7. Medidas de seguridad puestas a disposición por medios y empresas de comunicación

Fuente: Elaboración propia.

\begin{tabular}{cc}
\hline Dificultades para dormir y descansar & Miedo a la pérdida del empleo. \\
\hline Duelo. & $\begin{array}{c}\text { Inseguridades personales ante el nuevo } \\
\text { paradigma. }\end{array}$ \\
\hline Ansiedad. & Inestabilidad emocional. \\
\hline Estrés. & Trauma (choque o impresión emocional). \\
\hline Agotamiento. & Vulnerabilidad. \\
\hline Miedo al contagio. & Otras. \\
\hline
\end{tabular}

Tabla 8. Afecciones emocionales desarrolladas por los componentes de la muestra derivadas de la cobertura periodística del COVID-19

Fuente: Elaboración propia.

Del mismo modo, se solicitó información sobre las posibles restricciones durante el ejercicio profesional ligado a la pandemia. En el caso de haberlas sufrido, se ofrecía un espacio que, mediante respuestas abiertas, permitía responder con total libertad.

Por último y considerando la tercera hipótesis de la investigación, se preguntó específicamente si habían sufrido afecciones emocionales derivadas de la cobertura periodística del coronavirus y, de ser así, de qué tipo, dando la posibilidad de trece respuestas diferentes (tabla 8 ).

Entre las dificultades del estudio destacan dos. En primer lugar, el momento en el que se elaboró la investigación dificultó contrastar los datos con otras referencias académicas, dada la ausencia de estos estudios en el momento de desarrollo de este trabajo. Por ello, se optó por utilizar los resultados de los estudios de Fenaj y SiPreBa, también desarrollados con el apoyo de sindicatos de periodistas. Sin embargo, 
conviene destacar que el objeto de dichos estudios no era exactamente el mismo, por lo que solo se utilizaron los datos pertinentes para esta investigación. En segundo lugar, la heterogeneidad de la evolución del virus en los distintos países de América Latina promovió una aproximación regional para esta investigación, que será profundizada por medio de análisis nacionales en futuros trabajos.

\section{RESULTADOS}

Los resultados sociodemográficos de la encuesta permitieron diseñar una primera aproximación descriptiva al perfil de periodista durante la pandemia en América Latina, basado en el aumento de la precariedad laboral, la falta de protección sociosanitaria, tanto física como psicoemocional, y el desafío del teletrabajo durante los 100 primeros días de la COVID-19 en la región. Conviene remarcar que la investigación se basó en un cuestionario en línea de elaboración propia ad hoc para este estudio, completado por una muestra de afiliados de la Oficina Regional para América Latina y el Caribe de la Federación Internacional de Periodistas. Se trata de un cuestionario de elaboración propia destinado a periodistas y comunicadores de organizaciones sindicales del periodismo. Específicamente, dentro de la muestra de 95 respuestas, 25 personas respondieron desde Perú, lo que representa un $26,6 \%$, mientras que el segundo país con más respuestas fue México, con 19, es decir, $20,2 \%$ del total.

En cuanto a las características sociodemográficas de la muestra, $60 \%$ de los cuestionarios fueron respondidos por hombres y el restante $40 \%$, por mujeres. Las edades se concentran entre los 25 y los 60 años, hallándose en los 50 años la mayoría de las respuestas. Asimismo, la afiliación gremial o profesional se dividió prácticamente en tercios, entre los que pertenecen a un sindicato, los que no y los que adhieren a otro tipo de organización gremial (gráfico 1).

Una tendencia general que puede desprenderse de los resultados es que el impacto del coronavirus, unido a la recesión económica que algunos países de la región venían sufriendo, ha profundizado la precarización del trabajo en el periodismo latinoamericano. Al aglutinar y considerar distintas variantes relacionadas con despidos, el 15\% de informantes habían sufrido un cese en su actividad profesional durante los 100 días de existencia de la COVID-19 en América Latina. En esta categoría se consideran la eliminación de colaboraciones, la no renovación de contratos temporales, el recorte de tareas y los despidos directos en una relación de dependencia. Además, 16,7\% de los informantes declaró haber sido objeto de suspensiones, lo cual anuncia un posible crecimiento en el número de despidos (gráfico 2). 


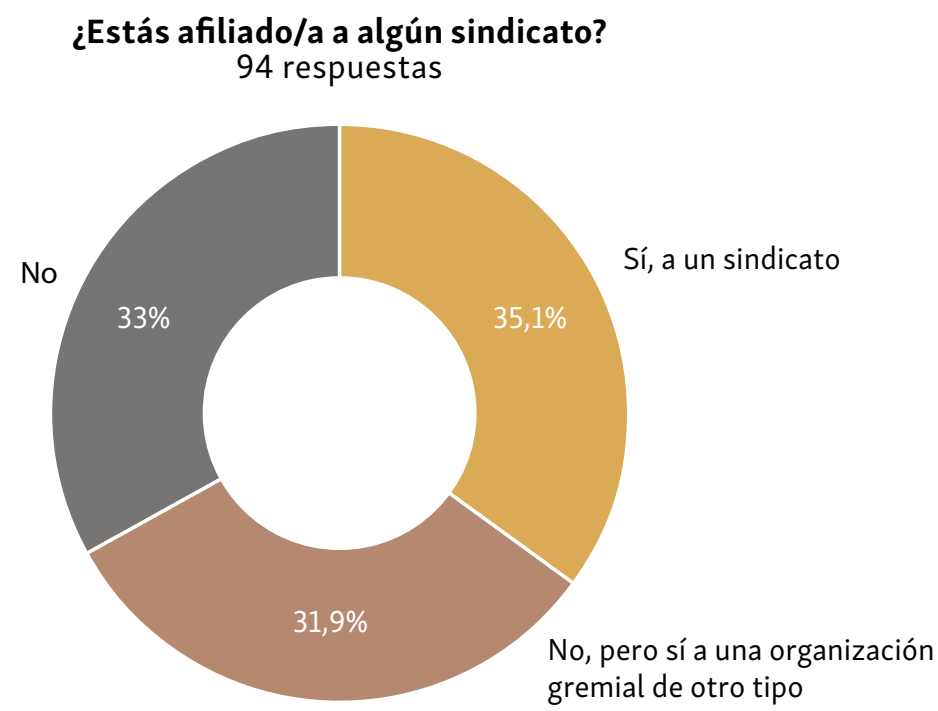

\section{Gráfico 1. Afiliación sindical o a organizaciones gremiales de los periodistas latinoamericanos}

Fuente: Elaboración propia.

\section{¿Ha cambiado tu situación laboral a causa del estado de aislamiento?}

94 respuestas

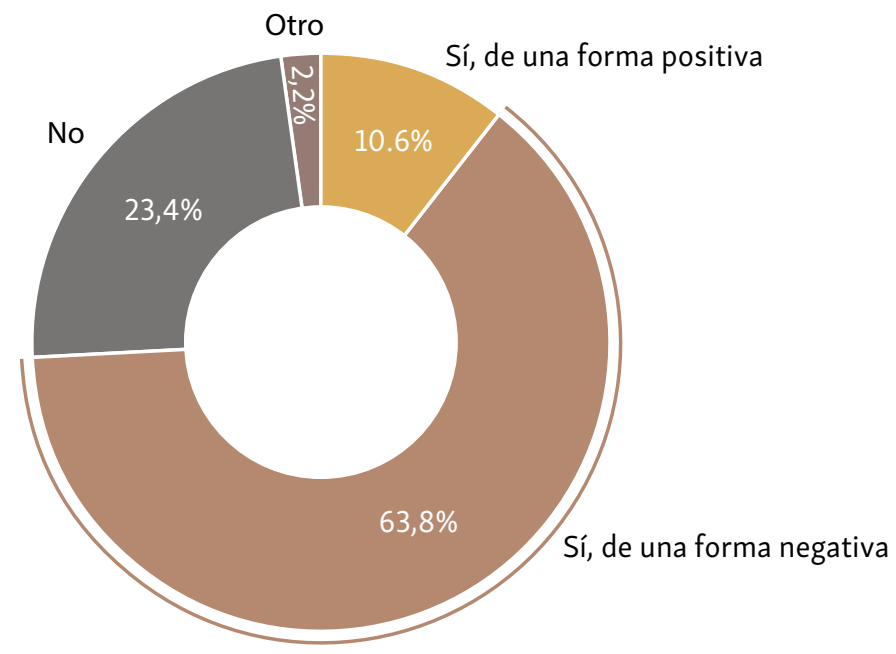

Gráfico 2. Modificaciones en la situación laboral de los periodistas latinoamericanos durante la pandemia

Fuente: Elaboración propia.

En lo que respecta a la titularidad del medio de comunicación, la mayoría trabaja en medios privados (57,8\%), mientras que solo 11,1\% presta servicios en públicos. El resto de la muestra se divide en servicios a cooperativas, medios comunitarios, instituciones, organizaciones no gubernamentales (ONG) y hasta partidos políticos. 
Especial atención merece la figura del autónomo o freelance en esta investigación (12,2\% de freelances o periodistas independientes y $8,9 \%$ comprendido en otro tipo de figura), ya que las consecuencias de una economía de pandemia han incidido especialmente en los periodistas autónomos. Antes de la declaración del estado de alarma o de emergencia social en algunos países de América Latina, el porcentaje de esta figura era de $35 \%$, con un notorio descenso en estos días: solo $12 \%$.

Otro desafío que se desprende de la investigación es el referido a la libertad de prensa. El 68\% declaró no sufrir restricciones en su desempeño profesional relacionado con el coronavirus. En el caso del 31,8\% que sí declaró mostrarse afectado por restricciones, estas iban desde cuestiones personales, como la relación con las autoridades (de salud y de seguridad, mayormente), hasta estructurales, como las prohibiciones de circular o de acceso a la información (gráfico 3).

Existe también lo que podríamos conceptualizar como reconversión laboral, es decir, la inmensa cantidad de periodistas que se vio forzada a realizar sus tareas mediante teletrabajo. En relación con la primera hipótesis secundaria (H2. El teletrabajo ha aumentado la precarización laboral de los periodistas en la región, suponiendo mayor carga laboral y mayores responsabilidades), los resultados muestran tres tendencias diferenciadas. En primer lugar, un tercio de las empresas ha mantenido inalterada la relación laboral de sus trabajadores, mientras que otro tercio ha estimulado la modalidad de teletrabajo y el tercio restante ha intentado distintas formas de reducción de jornadas laborales, ya sea eliminando tareas o no dotando del equipamiento adecuado para el trabajo remoto. Si se analiza con detenimiento el porcentaje de respuestas vinculadas con el teletrabajo, 32,4\% de los informantes trabaja más tiempo que antes, contra $13,5 \%$ que lo hace en menor medida; un $16,2 \%$ siente que trabaja lo mismo que previamente, pero con mayores complicaciones en la organización del trabajo y solo 8,1\% considera al teletrabajo como una modalidad efectiva y productiva.

Al examinar si los periodistas latinoamericanos habían tenido acceso a medidas de profilaxis y prevención sanitaria durante la pandemia, casi la mitad había recibido información de manera adecuada de parte de su empresa, mientras que la otra mitad se dividía entre informaciones tardías, insuficientes y otro tipo de irregularidades, con casi un $20 \%$ que aludía a la ausencia absoluta de la información necesaria (gráfico 4).

Por último, se ha indagado en torno a las afecciones psicoemocionales derivadas del clima sociolaboral generado por la COVID-19. En relación con el padecimiento de algún tipo de afección, casi 70\% respondió estar afectado, mientras que poco más de 30\% no reconoció ninguna afección (gráfico 5). 


\section{¿Has experimentado restricciones a la hora de desempeñar tu trabajo en el marco de la} cobertura informativa de la actual pandemia?

85 respuestas

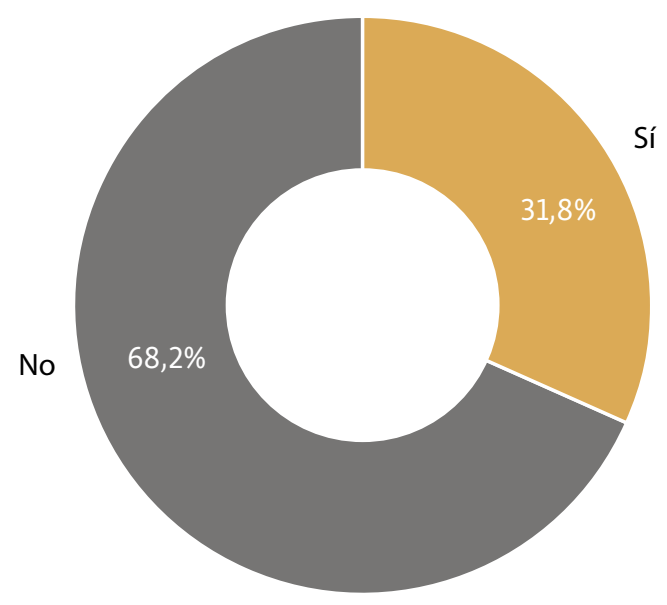

Gráfico 3. Restricciones en el desempeño periodístico durante la pandemia Fuente: Elaboración propia.

¿Tu empresa te ha informado sobre medidas de prevención del COVID-19?

93 respuestas

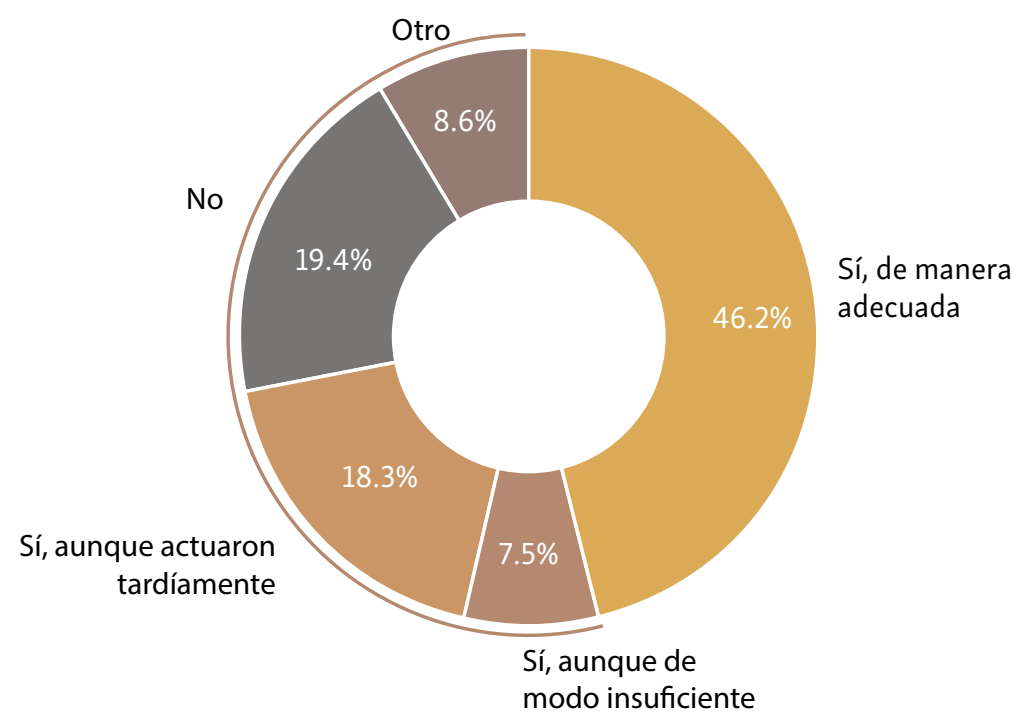

Gráfico 4. Acceso a medidas de prevención del COVID-19

Fuente: Elaboración propia. 


\section{¿Has padecido o estás padeciendo alguna afectación psico-emocional con motivo de la COVID-19 y el consecuente aislamiento?}

91 respuestas

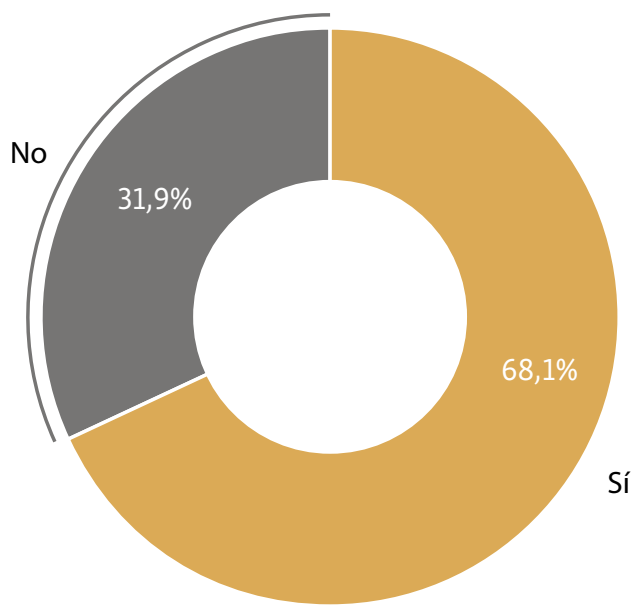

Gráfico 5. Consecuencias psicoemocionales en los periodistas latinoamericanos por COVID-19

Fuente: Elaboración propia.

En cuanto a la declaración del estado de aislamiento por la COVID-19 y las medidas adoptadas, ¿qué dificultades están encontrando para desempeñar tu labor de informar?

85 respuestas

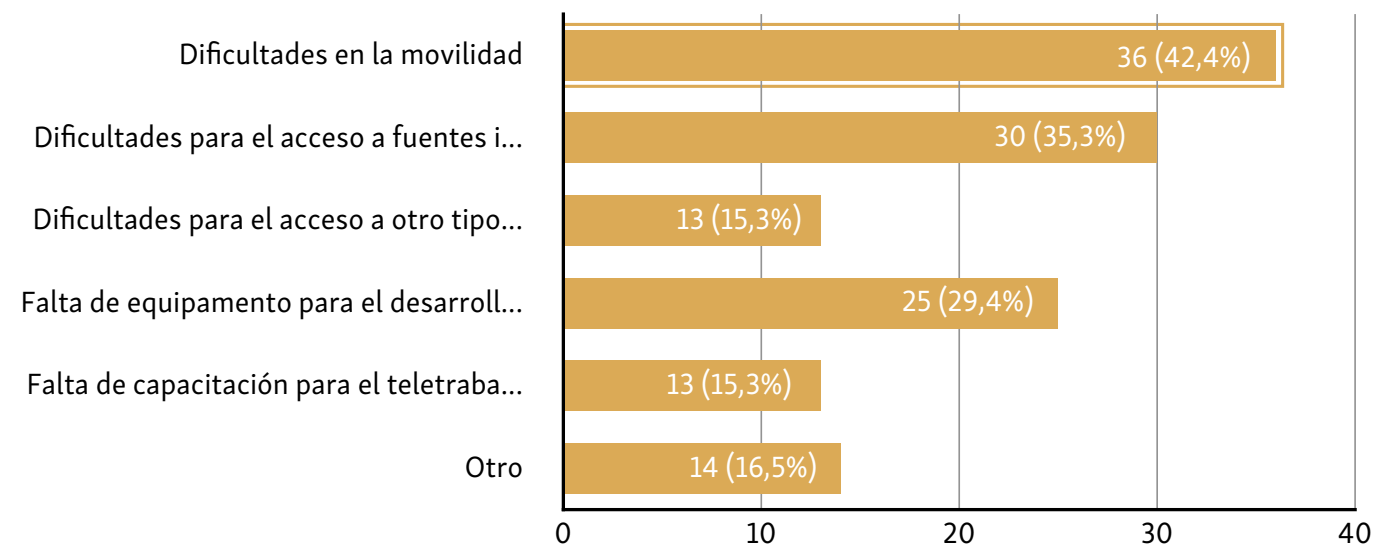

Gráfico 6. Dificultades para desempeñar la labor de informar debido al COVID-19

Fuente: Elaboración propia.

Al preguntar por las dificultades para desempeñar la labor de informar, más de la mitad ha confesado dificultades en la movilidad o bien en el acceso a fuentes. El resto de los informantes se repartían entre falta de equipamiento, falta de capacitación para el teletrabajo o dificultades en el acceso a otro tipo de herramientas (gráfico 6). 


\section{DISCUSIÓN}

Una vez desglosados los resultados de la investigación, la discusión contrastará los datos a escala regional con los de dos países donde se han realizado encuestas similares en el mismo período analizado, Brasil (Federação Nacional dos Jornalistas, 2020) y Argentina (Sindicato de Prensa de Buenos Aires, 2020), con el propósito de analizar las confluencias y divergencias de las tres propuestas. La encuesta de la Fenaj $(\mathrm{N}=451)$ fue realizada desde el 20 de mayo hasta el 10 de junio de 2020. A pesar de contar con una población considerablemente inferior a la de Argentina $(\mathrm{N}=700)$ y diferir en sus especificidades y ordenamiento, pueden trazarse ciertas tendencias con respecto a los datos de escala regional.

En primer lugar, es importante observar la seguridad laboral de los periodistas durante la pandemia del coronavirus en América Latina. El 79,2\% de los periodistas brasileños declaró haber observado despidos en su empresa, mientras que en Argentina el número se reduce a un 18\%, según los datos de SiPreBa (Sindicato de Prensa de Buenos Aires, 2020). La encuesta a nivel latinoamericano arroja un 1,5\% de despidos y 13,7\% de trabajadores que no obtuvieron la renovación de sus contratos temporales o eliminaron sus colaboraciones, así como 16,7\% de suspensiones, lo que augura un futuro profesional incierto para más de 31,5\% de los informantes.

Con respecto al teletrabajo durante la pandemia, en Brasil (75,2\%) y Argentina (75\% durante y $10 \%$ antes) esta opción supera ampliamente los datos regionales $(32,6 \%)$. Ello podría derivarse de una mayor formalidad en los dos países sudamericanos en comparación con otros de la región, pero esta sería una hipótesis para futuras investigaciones.

Al preguntar específicamente por el impacto de estos modos de trabajo, las tres encuestas ilustran sobre formas de precarización laboral crecientes a través del teletrabajo y del uso de las nuevas tecnologías: $55 \%$ de los periodistas brasileños declaró ver engrosada su carga de trabajo debido a la reducción de personal. En la encuesta argentina, 82,5\% de los periodistas respondió que no contaban con el mobiliario necesario, lo que dificultaba su labor profesional. A nivel regional, $32,4 \%$ trabajó más tiempo que antes del coronavirus, mientras que 29,4\% indicó una falta de equipamiento adecuado. Todo esto revela un contex to preocupante de precarización de la fuerza de trabajo con la excusa del trabajo remoto, posiblemente utilizado por el empresariado a modo de cobertura por los despidos y suspensiones.

Porúltimo, se observa una tendencia referida a las secuelas psicológicas derivadas de las coberturas de la COVID-19 y, en muchas ocasiones, de las propias condiciones laborales impuestas por las empresas mediáticas. Más de la mitad de los periodistas brasileños $(55,5 \%)$ se ha visto afectada emocionalmente, citando episodios de estrés o sobrecarga de trabajo, mientras que sus compañeros argentinos aludían a una 
mayor presión laboral. A escala regional, estos datos llegan a casi tres de cada cuatro informantes $(68,1 \%)$ que declaran estar padeciendo afecciones emocionales como el ya citado estrés, dificultades para dormir o ansiedad. Cabe recordar para finalizar el "energético llamado a garantizar el rol trascendental que cumple la prensa en contextos de pandemia, de acuerdo con la Resolución 1/20 sobre Pandemia y Derechos Humanos emitida por la Comisión Interamericana" que tanto la Relatoría Especial de Libertad de Expresión (RELE, 2020) de la Comisión Interamericana de Derechos Humanos (CIDH) como el Plan de Acción de Naciones Unidas para la Seguridad de los Periodistas y la cuestión de la Impunidad (Unesco, 2018) señalan la importancia de la prevención y la protección de los periodistas, incluyendo una capacitación adecuada para minimizar los riesgos en las coberturas periodísticas.

\section{CONCLUSIONES}

Estainvestigación ha permitido verificar que la pandemia de COVID-19 ha agravado, durante los 100 primeros días en América Latina, problemas estructurales del periodismo en la región. Si bien la diversidad profesional en la zona y las limitaciones propias de la investigación, justifican las particularidades de una muestra con un perfil específico, también permiten discernir algunas ideas fuerzas sobre el colectivo, que serán profundizadas en futuras líneas de investigación. En este sentido, se han precarizado aún más las condiciones laborales y, como consecuencia, las afecciones psicológicas han alcanzado a un alto porcentaje de los trabajadores de prensa.

Tras analizar críticamente los datos resultantes de la encuesta a miembros de la Federación Internacional de Periodistas en 16 países de la región y contrastarlos con estudios nacionales de países que han tenido políticas públicas diversas en materia de prevención de la pandemia -Brasil y Argentina- se ha verificado la primera hipótesis secundaria, que aludía a una reconversión laboral acelerada en el sector por el impacto de la pandemia. Ello se observa en dos fenómenos principales: la reducción de personal se ha consolidado como una constante a nivel regional entre marzo y junio de 2020 mediante despidos, eliminación de colaboraciones, no renovación de los profesionales o suspensión de pagos y, como consecuencia, los periodistas latinoamericanos que continúan trabajando en plantilla están experimentando un aumento considerable de la carga laboral, en muchos casos derivada de un uso pernicioso y abusivo del teletrabajo.

Por último, el impacto del coronavirus y el agravamiento de la precarización laboral han provocado que siete de cada diez profesionales latinoamericanos hayan experimentado secuelas psicológicas severas, verificándose asíla segunda y última hipótesis secundaria de la investigación. Frente a ello, la autoprotección individual y colectiva de los profesionales de la información ha generado que deban tomar sus propias medidas de seguridad, lo que ha repercutido en gran cantidad de tipos de afecciones emocionales. 


\section{FINANCIAMIENTO}

El estudio fue realizado durante una estancia de investigación de la doctora Ruth de Frutos en la Universidad de Buenos Aires (Argentina), financiada por el plan propio de investigación de la Universidad de Málaga (convocatoria 2020) y con la colaboración de la Oficina Regional para América Latina y el Caribe de la Federación Internacional de Periodistas.

\section{REFERENCIAS}

Banco de Desarrollo de América Latina. (2020). El estado de la digitalización de América Latina frente a la pandemia del COVID-19 (The state of digitization of Latin America in the face of the COVID-19 pandemic). CAF. https://scioteca.caf.com/handle/123456789/1540

BBC News. (2020, February 26). Coronavirus: Brasil confirma el primer caso en América Latina (Coronavirus: Brazil confirms the first case in Latin America). BBC News. https://www.bbc.com/mundo/noticias-america-latina-51641436

Becerra, M. \& Mastrini, G. (2009). Los dueños de la palabra. Acceso, estructura y concentración de los medios en la América Latina del siglo XXI. Buenos Aires: Prometeo.

Becerra, M. \& Mastrini, G. (2017). La concentración infocomunicacional en América Latina (2000-2015). Nuevos medios $y$ tecnologías, menos actores (The infocommunication concentration in Latin America (2000-2015). New media and technologies, fewer players). Universidad Nacional de Quilmes.

Botero Marino, C. (2014). Violencia contra periodistas y trabajadores de medios: Estándares interamericanos $y$ prácticas nacionales sobre prevención, protección y procuración de justicia (Violence Against Journalists and Media Workers: Inter-American Standards and National Practices on Prevention, Protection, and Law Enforcement).

http://www.oas.org/es/cidh/expresion/docs/informes/2014_04_22_violencia_esp_web.pdf

Caminos, E. D. (2020). El mundo del trabajo y la precariedad laboral de los comunicadores y periodistas (The labor world and job insecurity for communicators and journalists). Revista de Estudio de Derecho Laboral y Derecho Procesal Laboral, (2), 27-38. https://revistas.ubp.edu.ar/index.php/derecho-laboral/article/view/204

Casero-Ripollés, A. (2020). Impact of COVID-19 on the media system. Communicative and democratic consequences of news consumption during the outbreak. Profesional De La Información, 29(2), e290223. https://doi.org/10.3145/epi.2020.mar.23

Castells, M. (2009). Comunicación y Poder (Communication and Power). Alianza Editorial.

CEPAL \& CAF. (2020). Las oportunidades de la digitalización en América Latina frente al COVID-19 (The opportunities of digitization in Latin America in the face of COVID-19). http://hdl.handle.net/11362/45360 
Comité por la Libre Expresión. (2020, April 24). Policías retienen a foto-reportero al "confundirlo" con un supuesto agente de inteligencia (Police detain a photojournalist, "mistaking" him for an alleged intelligence agent). C Libre Honduras.

http://clibrehonduras.com/index.php/portada-alertas/1153-policias-retienen-a-fotoreportero-al-confundirlo-con-un-supuesto-agente-de-inteligencia

Convención Americana Sobre Derechos Humanos Suscrita en la Conferencia Especializada Interamericana Sobre Derechos Humanos (B-32) (American Convention on Human Rights Signed at the Inter-American Specialized Conference on Human Rights (B-32)). (1969). https://www.oas.org/dil/esp/tratados_b-32_convencion_americana_sobre_derechos_ humanos.htm

Corte Interamericana de Derechos Humanos. (2020a, April 14). COVID-19 y derechos humanos: los problemas $y$ desafios deben ser abordados con perspectiva de derechos humanos $y$ respetando las obligaciones internacionales (COVID-19 and human rights: problems and challenges must be approached from a human rights perspective and respecting international obligations). http://www.corteidh.or.cr/tablas/alerta/comunicado/cp-27-2020.html

Costa-Sánchez, C. \& López-García, X. (2020). Comunicación y crisis del coronavirus en España. Primeras lecciones (Communication and coronavirus crisis in Spain. First lessons). El profesional de la información, 29(3), e290304. https://doi.org/10.3145/epi.2020.may.04

de Frutos, R. (2014). Indicadores mediáticos: análisis crítico de los modelos de evaluación internacional (Media indicators: critical analysis of international evaluation models) (Doctoral disssertation, Universidad de Málaga). https://riuma.uma.es/xmlui/handle/10630/8569

de Frutos, R. \& Giannone, D. (2018): Mudanças metodológicas e desafíos na medição da libertade de informação. Uma análise dos índies Repórteres Sem Fronterias e Freedom House (Methodological changes and challenges in the measurement of freedom of information. An analysis of the Reporters Without Borders and Freedom House indexes). Comunicação e Sociedade, (33), 271-290.

Delgado, M. (2020, April 2). Desafiando los temores de pandemia, el gobierno nicaragüense rechaza el distanciamiento social (Defying pandemic fears, Nicaraguan government rejects social distancing). Miami Herald. https://www.miamiherald.com/news/nationworld/world/americas/article241706736.html

Díaz Nosty, B. (2018). Díez años que cambiaron los medios (Ten years that change the media). Ariel.

Estrada-Villaseñor, C. \& Moreno-Márquez, G. (2021). El impacto de la Covid-19 sobre el periodismo de inmigración en España: continuidades aceleradas y posibles rupturas (The impact of Covid-19 on immigration journalism in Spain: accelerate continuities and posible breakdowns). Estudios sobre el Mensaje Periodístico, 27(1), 111-121. https://doi.org/10.5209/esmp.71429

Federación Internacional de Periodistas. (2020). IFJ Coronavirus (COVID-19) Safety Advisory for Media Professionals. https://www.ifj.org/fileadmin/user_upload/IFJ_Coronavirus_ Safety_Advisory_-_English.pdf 
Garces-Prettel, M., Arroyave-Cabrera, J., \& Baltar-Moreno, A. (2020). Professional Autonomy and Structural Influences: Exploring How Homicides, Perceived Insecurity, Aggressions Against Journalists, and Inequalities Affect Perceived Journalistic Autonomy in Colombia. International Journal of Communication, 14. https://ijoc.org/index.php/ijoc/article/view/11925/3109

Glik D. C. (2007). Risk Communication for Public Health Emergencies. Annual Review of Public Health, 28(1), 33-54. https://doi.org/10.1146/annurev.publhealth.28.021406.144123

Human Rights Watch. (2020a, March 26). México: los mexicanos necesitan información precisa sobre COVID-19 (Mexico: Mexicans need accurate information on COVID-19). Humans Rights Watch. https://www.hrw.org/news/2020/03/26/mexico-mexicans-needaccurate-covid-19-information

Human Rights Watch. (2020b, April 10). Brasil: Bolsonaro sabotea los esfuerzos anti-COVID-19 (Brazil: Bolsonaro sabotages anti-COVID-19 efforts). Humans Rights Watch. https://www.hrw.org/news/2020/04/10/brazil-bolsonaro-sabotages-anti-covid-19-efforts

La Declaración Universal de los Derechos Humanos. Resolución 217 A (III) (The Universal Declaration of Human Rights. Resolution 217 A (III)). (1948, December 10). Retrieved from https://www.un.org/es/universal-declaration-human-rights/

La, V. P., Pham, T. H., Ho, M. T., Nguyen, M. H. P., Nguyen, K. L., Vuong, T. T., Nguyen, H. K. T., Tran, T., Khuc, Q., Ho, M. T., \& Vuong, Q. H. (2020). Policy Response, Social Media and Science Journalism for the Sustainability of the Public Health System Amid the COVID-19 Outbreak: The Vietnam Lessons. Sustainability, 12(7), 2931. https://doi.org/10.3390/su12072931

Lanza, E. (2017). Estándares para una Internet libre, abierta e incluyente (Standards for a free, open and inclusive Internet). http://www.oas.org/es/cidh/expresion/docs/ publicaciones/internet_2016_esp.pdf

Li, L., Zhang, Q., Wang, X., Zhang, J., Wang, T., Gao, T. L., Duan, W., Tsoi, K. K., \& Wang, F. Y. (2020). Characterizing the Propagation of Situational Information in Social Media During COVID-19 Epidemic: A Case Study on Weibo. IEEE Transactions on Computational Social Systems, 7(2), 556-562. https://doi.org/10.1109/TCSS.2020.2980007

Mastrini, G. \& Becerra, M. (2006). Periodistas y Magnates. Estructura y concentración de las industrias culturales en América Latina (Journalists and Tycoons. Structure and concentration of cultural industries in Latin America). Prometeo.

Navarro Zamora, L. (2021). Condiciones de trabajo cotidiano de los periodistas de América Latina en la cobertura del fenómeno COVID-19, estudio descriptivo emergente (Daily working conditions of journalists in Latin America in the coverage of the Covid-19 phenomenon, an emerging descriptive study). ZER: Revista de Estudios de Comunicación= Komunikazio Ikasketen Aldizkaria, 26(50), 223-240. https://doi.org/10.1387/zer.21963

Organización Internacional del Trabajo. (2020). Observatorio de la OIT: El COVID-19 y el mundo del trabajo. Cuarta edición Estimaciones actualizadas y análisis (ILO Observatory: COVID-19 and the world of work. Fourth Edition Updated Estimates and Analysis). https://www.ilo.org/wcmsp5/groups/public/@dgreports/@dcomm/documents/ briefingnote/wcms_745965.pdf 
Pacto Internacional de Derechos Civiles y Políticos (International Covenant on Civil and Political Rights). (1966, December 16). https://www.ohchr.org/SP/ProfessionalInterest/Pages/CCPR.aspx

Pandemia y Derechos Humanos en la Pandemia. Resolución 1/2020 (Pandemic and Human Rights in the Pandemic. Resolution 1/2020) (2020, April 10). http://oas.org/es/cidh/decisiones/pdf/Resolucion-1-20-es.pdf

Papapicco, C. (2020). Informative Contagion: The Coronavirus (COVID-19). Italian journalism. Online Journal of Communication and Media Technologies, 10 (3), e202014. https://doi.org/10.29333/ojcmt/7938

Punín, M. I., Sánchez, G., \& Barrazueta, P. (2021). COVID-19 en Ecuador: luto en el periodismo y zozobra informativa (COVID-19 in Ecuador: journalism in mourning and information anxiety). Revista Temas Sociológicos, (28), 83-111. https://doi. org/10.29344/07196458.28.2773

Relatoría Especial de Libertad de Expresión (RELE) de la Comisión Interamericana de Derechos Humanos (CIDH) (2020, April 18). CIDH y su RELE expresan preocupación por las restricciones a la libertad de expresión y el acceso a la información en la respuesta de Estados a la pandemia del COVID-19 (IACHR and its SR FOE express concern about restrictions on freedom of expression and access to information in State's response to the COVID-19 pandemic). https://www.oas.org/es/cidh/expresion/showarticle. asp?artID $=1173 \& 1 \mathrm{ID}=2$

Retegui, L. \& Becerra, M. (2020, June 16). La grieta entre los medios y el público (The gap between the media and the public). Quipu. https://martinbecerra.wordpress. com/2020/06/21/la-grieta-entre-los-medios-y-el-publico/

Reuters Institute. (2020). Navigating the 'infodemic': how people in six countries access and rate news and information about coronavirus. Reuters Institute for the Study of Journalism. https://cutt.ly/ZyiIISy

Rodrigo Cano, D. \& Ruiz-Alba, N. (2021). El (des)empleo en la profesión de periodista en tiempos de pandemia ((Un) employment in the journalism profession in times of pandemics). Ámbito. Revista Internacional de Comunicación, 52, 27-36. https://doi.org/10.12795/Ambitos.2021.i52.02

Sindicato de Periodistas de Andalucía. (2020, June 4). El SPA condena y lamenta el cierre de Alpujarra Radio, único medio comarcal de la Alpujarra granadina, creada en 2010 con fondos europeos (The SPA condemns and regrets the closure of Alpujarra Radio, the only regional medium in Granada's Alpujarra, created in 2010 with European funds). Sindicato de Periodistas de Andalucía. https://www.spandalucia.com/category/comunicados-spa/

Sindicato de Prensa de Buenos Aires. (2020). Encuesta sobre salarios, teletrabajo y condiciones laborales 2020: dos de cada tres trabajadores/as de prensa cobró un salario por debajo de la Canasta (2020 Survey on salaries, teleworking and working conditions: two out of three press workers received a salary below the norm). SiPreBa. https://www. sipreba.org/sindicato/encuesta-sobre-salarios-teletrabajo-y-condiciones-laborales-2020/

Soengas-Pérez, X. (2018). The role of the Internet and social networks in the Arab uprisings: An alternative to official press censorship. Comunicar, 21(41), 147-156. Retrieved fromhttp://eprints.rclis.org/19787/ 
Unesco. (2018). Plan de Acción de las Naciones Unidas sobre la Seguridad de los Periodistas y la Cuestión de la Impunidad (Safety of journalists and the issue of impunity). https://unesdoc.unesco.org/ark:/48223/pfo000232337_spa

Unesco. (2019). Tendencias mundiales en libertad de expresión y desarrollo de los medios: informe regional para América Latina y el Caribe 2017/2018 (World trends in freedom of expression and media development: regional overview of Latin America and the Caribbean 2017/2018). Oficina Regional de Unesco. https://unesdoc.unesco.org/ark:/48223/pf0000366564

Unesco. (2020). Periodismo, libertad de prensa y COVID-19: nota temática de la serie de la Unesco (Journalism, press freedom and COVID-19). https://unesdoc.unesco.org/ark:/48223/pfo000373573_spa

VV. AA. (2020, april 2). Declaración conjunta de la sociedad civil: Los Estados deben respetar los derechos humanos al emplear tecnologías de vigilancia digital para combatir la pandemia (Joint Civil Society Statement: States use of digital surveillance technologies to fight pandemic must respect human rights). https://www.hrw.org/ es/news/2020/04/02/declaracion-conjunta-de-la-sociedad-civil-los-estados-debenrespetar-los-derechos

\section{SOBRE LOS AUTORES}

RUTH DE FRUTOS GARCíA, profesora del departamento de Periodismo de la Universidad de Málaga (UMA)y periodista. Doctora en Periodismo (UMA) y licenciada en Periodismo (Universidad de Valladolid). Sus líneas de investigación se centran en periodismo, derechos humanos y feminismos. Entre sus últimos trabajos destaca Misinformation and migration during the COVID-19 pandemic: From the migrant caravan in Honduras to the Filipino diaspora, publicado por la Organización Internacional de las Migraciones (2021).

(iD) https://orcid.org/0000-0001-9380-2798

SEBASTIÁN JAVIER SANJURJO, responsable de proyectos de la Oficina Regional para América Latina y el Caribe de la Federación Internacional de Periodistas. Licenciado en Sociología por la Universidad de Buenos Aires (UBA). Entre sus últimos trabajos destaca Hacia un mundo digitalizado publicado en Nueva Sociedad (2021). 